\title{
Manifestation of Borderline Personality Symptomatology in Chronic Pain Patients Under Stress: An Understated and Exacerbated Consequence of the COVID-19 Crisis
}

This article was published in the following Dove Press journal:

Journal of Pain Research

\author{
Hannah Shapiro (1D \\ Ronald J Kulich $\mathbb{1}^{2,3}$ \\ Michael E Schatman (iD) 3,4 \\ 'Department of Biopsychology, Tufts \\ University, Medford, MA, USA; \\ ${ }^{2}$ Department of Anesthesia, Critical Care \\ and Pain Medicine, Harvard Medical \\ School/Massachusetts General Hospital, \\ Boston, MA, USA; ${ }^{3}$ Department of \\ Diagnostic Sciences, Tufts University \\ School of Dental Medicine, Boston, MA, \\ USA; ${ }^{4}$ Department of Public Health and \\ Community Medicine, Tufts University \\ School of Medicine, Boston, MA, USA
}

Correspondence: Michael E Schatman $\mathrm{Tel}+$ I $425647-4880$

Email Michael.Schatman@tufts.edu

\section{Introduction}

To the best of our knowledge, no one has ever suggested that it is "easy" to suffer from intractable chronic pain, with some subgroups impacted more than others. This burden has had a particularly strong impact in the United States, where the chronic pain treatment system has demonstrated failings with respect to access to care $^{1-8}$ Because chronic pain is so poorly treated in the United States, patients have struggled not only with their pain and its sequelae but also with mounting frustration and downstream psychological consequences. Depression and suicidality have been linked to poorly controlled pain, ${ }^{9,10}$ and the authors of a recent study ${ }^{11}$ noted that these phenomena are a concern within the context of opioid tapering. Similarly, Lembke has recently acknowledged that even mention of tapering can trigger severe anxiety in chronic pain patients, ${ }^{12}$ with data supporting the relationship between undertreated chronic pain and anxiety. ${ }^{13,14}$ Although myriad investigations have supported the existence of a reciprocal relationship between chronic pain and depression ${ }^{15-17}$ as well as between chronic pain and anxiety, ${ }^{18-20}$ detailed discussion of causality is beyond the scope of this analysis.

\section{Personality Disorders and Chronic Pain}

Although depression and anxiety have been the most investigated psychological sequelae of chronic pain, they are hardly the only psychological conditions for which chronic pain sufferers are overrepresented. Several early reports and studies suggested that patients with personality disorders were significantly overrepresented in the chronic pain patient population. ${ }^{21-24}$ However, these studies were not particularly methodologically-robust, as clear issues of selection bias, small sample sizes, and reliance only upon semi-structured psychiatric interviews detracted from their validities. It was not until Gatchel et $\mathrm{al}^{25}$ published their prospective multi-site investigation of clinical predictors of psychopathology as strongly relating to low back pain patient outcomes in 1995 that more formidable scientific rigor was used to determine the incidence of personality disorders in the chronic pain population. The authors used a combination of a structured clinical interview and a 120 -item patient questionnaire relating to the structured interview 
in addition to the Minnesota Multiphasic Personality Inventory (MMPI) to determine diagnoses for 324 chronic low back pain patients. Subjects were deemed either "disabled" or "nondisabled" based upon their current vocational statuses, with $36.1 \%$ of the disabled patients but only $22.3 \%$ of the nondisabled group identified as suffering from a personality disorder.

Beyond the mere diagnosis of a personality disorder is the type of personality disorder from which a patient suffers. Based on the American Psychiatric Association's Diagnostic and Statistical Manual of Mental Disorders (DSM) ${ }^{26}$ there are 3 "clusters" of personality disorders. Cluster A personalities include the paranoid, schizoid, and schizotypal, and these patients are often described as "odd or eccentric". Cluster B personalities include the antisocial, borderline, histrionic, and narcissistic, and patients with such disorders are described as "dramatic, emotional, or erratic". Finally, Cluster C personalities include the avoidant, dependent, and obsessive-compulsive, and are generally described as "anxious or fearful". In pain management settings, it is the Cluster B patients who have received the most attention and raise the highest level of concern. In 1996, Elliot et $\mathrm{al}^{27}$ published the first study examining the prevalence of personality disorders in chronic pain patients in an outpatient program using a psychometric measure (the Millon Clinical Multiaxial Inventory (MCMI)) that had been validated for the identification of the specific personality disorders. The MCMI profiles yielded evidence of a personality disorder in $66 \%$ of the study's sample, with $19 \%$ identified as suffering from Cluster B personality disorders. Not surprisingly, higher Narcissism Scale scores were associated with higher pain scale ratings at discharge, with higher Borderline Scale scores associated with earlier discharge from the program.

\section{Borderline Personality Disorder and Chronic Pain}

Of great concern to pain clinicians is the dramatic overrepresentation of patients with a comorbid Borderline Personality Disorder (BPD) (or even severe borderline personality features without meeting the full diagnostic criteria for a BPD diagnosis) in the chronic pain population. An excellent summary of the DSM- 5 criteria for BPD can be found at: http://www.bpddemystified.com/what-isbpd/symptoms/. While data suggest a point prevalence of BPD in the general population of only $1.6 \%,{ }^{28}$ figures as high as $62.5 \%$ among chronic pain patients have been identified in the empirical literature. ${ }^{29}$ Little work has been published on the prevalence of BPD in specific pain syndromes, although a 2012 study indicated that BPD patients are significantly over-represented in the fibromyalgia population. ${ }^{30}$ It has been noted that the percentage of patients with BPD in medical settings may be underestimated, as they are often simply identified as "difficult patients" rather than being diagnosed with BPD. ${ }^{31}$ Further, it has been determined that patients with BPD's pain complaints are more difficult to medically substantiate than those without the characterological disturbance. ${ }^{32}$

Highlighting the issues that result in Cluster B Personalities' presentations as challenging patients, Sansone and Sansone ${ }^{33}$ authored a review in 2007, focusing on specific strategies for treating chronic pain patients with comorbid BPD. The "paradox" of which they wrote are findings that while those with BPD seem impervious to self-inflicted pain (common among BPDs), their tolerance for non-self-inflicted pain has been found in numerous studies to be considerably lower than in patients without this Cluster B disorder. The authors also note challenges associated with findings of BPD patients' higher prevalence of prescription opioid misuse, noting their tendency toward impulsivity and difficulties with self-regulation. This emotional dysregulation has been determined to contribute to pain sensitivity. ${ }^{34}$ Further, BPD patients are likely to report higher levels of pain than patients with other personality disorders. ${ }^{35}$ Regarding treatment of chronic pain patients with BPD, Sansone and Sansone ${ }^{33}$ emphasize the importance of helping patients understand that analgesics are unlikely to fully treat their pain, the benefits of non-opioid medications, the benefits of nonpharmacological approaches, conservative use of opioid analgesics, and careful monitoring of all opioid prescriptions. Frequent, brief appointments are suggested, along with the establishment of firm boundaries. Not surprisingly, a 2013 study by Tragesser et al determined that BPD in non-pain patients was associated with greater frequency and quantity of opioid abuse, higher risk for misuse as measured by the Revised Screener and Opioid Assessment for Patients with Pain (SOAPP-R), and more severe opioid-related consequences and dependence features. ${ }^{36}$ More severe borderline features were associated with an even greater risk of abuse. An earlier study indicated that $15 \%$ of patients suffering from BPD had histories of opioid abuse or dependence. ${ }^{37}$ Sansone et al came to similar conclusions among primary care 
outpatients with histories of opioid prescription, determining that those with BPD were at greater risk for abuse of prescription pain medications. ${ }^{38}$ The literature has also addressed similar issues regarding demands for excessive opioid analgesics in patients with BPD in palliative care settings. ${ }^{39}$ The authors of a recent investigation in which patients with chronic pain with comorbid BPD were more likely to misuse prescription opioids attributed this phenomenon to BPD sufferers' unstable identities and selfharmful impulsivity. ${ }^{40}$

In a later analysis, Sansone and Sansone ${ }^{41}$ suggest that BPD symptomatology is often used to interpersonally engage others, with these symptoms, either consciously or unconsciously, used to elicit caretaking from those around them. However, given their tendencies toward unstable interpersonal relationships, extreme mood swings, and explosive anger, these relationships with health-care providers are unlikely to be maintained. This is consistent with Kalira et al's assessment, ${ }^{42}$ in which they note that patients with BPD are prone to provoking anger and frustration in others, potentially resulting in providers doubting the veracity of their symptoms.

Suicidality has been documented as quite prevalent in borderline personalities, with an average of 3 suicide attempts during their lifetimes - primarily involving overdose. ${ }^{43}$ Further, other self-injurious behaviors (eg, superficial wrist cutting not intended to result in death but rather to relieve emotional tension) are also common among those with BPD, ${ }^{44}$ with these "parasuicides" too often resulting in unintended deaths. Importantly, longitudinal data have suggested that up to $10 \%$ of those suffering from BPD ultimately commit suicide. ${ }^{45}$ Unfortunately, a recent review concluded that there are no evidencebased guidelines for suicide prevention in BPD. ${ }^{46}$ For purposes of this analysis, it is important to consider a 2006 study that found that individuals with chronic pain are 2-3 times more likely to commit suicide than those without chronic pain ${ }^{47}$ - independent of personality disorder status. Similarly, Braden and Sullivan determined in a 2008 investigation that borderline personality traits were predictive of suicide among patients with selfreported chronic pain conditions. ${ }^{48}$ In 2015 , the initial investigation of the specific relationship between chronic pain, BPD, and suicidality was published. ${ }^{49}$ BPD was associated with the utilization of higher dosages of opioids, the use of benzodiazepines and antidepressants, and medication nonadherence. Not surprisingly, those patients with BPD reported 6.6 times the likelihood of suicidal ideation over the past 12 months and 7.9 times the likelihood of a past-12-month suicide attempt compared to those without BPD.

Yet another concern regarding comorbid chronic pain and BPD are findings that chronic pain sufferers with BPD are more likely to be receiving disability compensation than are those without BPD. For example, early work by Burton et $\mathrm{al}^{50}$ determined that workers compensation patients with BPD were less likely to return to work following functional restoration. A small 2003 study $^{51}$ also found a positive relationship between disability and borderline personality symptoms, with the authors concluding from their finding that the perception of greater disability in the borderline personality group as representing an "unconscious tendency to reestablish their life roles as victims" (p. 442). Two European studies ${ }^{52,53}$ similarly identified a strong positive association between the use of disability benefits/pensions and BPD. Most recently, BPD features were associated with a greater likelihood of receiving disability for chronic pain, even when the authors controlled for anxiety, depression, and other aspects of patients' pain. ${ }^{54}$ The authors offered 3 explanations for their findings. First, negative interpersonal relationships can cause problems with maintaining employment. Second, that those with BPDs have diminished social support networks that could provide a buffer to stress may result in an inability to function at a sufficiently high level to maintain employment. Most relevant to this analysis, the third explanation offered is that those with BPD are more likely to find themselves in conflictual relationships with health-care providers, thus interfering with the quality of care they receive and, consequently, less favorable pain care outcomes.

\section{"Diathesis-Stress", Borderline Personality, and Chronic Pain}

Many individuals who present at any given time with symptoms of BPD do not do so throughout their lives. In fact, many may carry what are essentially "latent" features of BPD until stress levels become so overwhelming that borderline personality features become manifest. Despite the DSM$\mathrm{V}^{\prime} \mathrm{s}^{26}$ characterization of the traits that define BPD as "enduring", there exists considerable disagreement regarding this concept. Crowell et al, ${ }^{55}$ among numerous others, have suggested a purely psychosocial model of BPD, while others, such as Perez-Rodriguez et al, ${ }^{56}$ have more recently focused on the neurobiological underpinnings of the disorder. 
A biopsychosocial conceptualization of BPD could combine these two positions, and numerous experts ${ }^{57-60}$ on the disorder have considered a biological predisposition toward BPD to put certain individuals at greater risk for the onset of the disorder and more severe manifestations of its symptoms when under considerable psychosocial stress. A diathesis-stress model has also been proposed to help understand why certain individuals will develop chronic pain while others will not do so. Among the early proponents of such a model were Flor and Turk, ${ }^{61,62}$ who conceptualized chronic pain as an interaction between biological and psychological predispositions (diathesis) and the stress of injury and resulting disability. The copious body of empirical investigation supporting the model has been reviewed in a textbook chapter by Weisberg and Keefe. ${ }^{63}$ Most relevant to this analysis is the work by Weisberg and Keefe, ${ }^{64}$ Weisberg, ${ }^{65}$ and Weisberg et al ${ }^{66}$ on the possibility that stress of chronic pain and the losses associated with it serving to "trigger" personality disorders to which a patient had been predisposed, yet had not yet manifested themselves. These authors have posited the existence of a bidirectional relationship between chronic pain and personality disorders, as well as claiming that their model provides a rational explanation for the over-representation of personality disorders in the chronic pain population that was discussed earlier in this analysis. Supporting this explanation is their observation that descriptions of many chronic pain patients' premorbid personality functioning differ dramatically from those observed following the development of their chronic pain. As discussed earlier, whether the predisposing diathesis or diatheses are psychosocial, physiological, or a combination of the two has yet to be firmly established empirically. More relevant is the conceptualization of chronic pain as a "disease of the person" that affects the sufferer beyond the physical sensation of pain itself. Rather, chronic pain affects individuals' qualities of life by causing potential deficits in function and can have a dramatic impact on a patient vocationally, financially, legally, recreationally, socially, sexually, emotionally, and even spiritually.

\section{The COVID-I 9 Crisis, Chronic Pain, and Borderline Personality Expression: A Potentially Bad Storm}

To this point, we have elucidated the challenges associated with being a patient with the comorbidities of chronic pain and BPD, as well as treating such patients under normal circumstances. The worldwide COVID-19 crisis has greatly exacerbated these challenges, which will be discussed in the remainder of this analysis.

Accepting the diathesis-stress model of chronic pain and BPD, the role of stress in exacerbating pain symptoms cannot be understated. Whether infected with the virus, living with loved ones who are infected or in a high-risk category, or fearing for our lives and/or livelihoods, everyone is under a heightened sense of stress. Much has been written about the levels of individual and societal stress associated with the crisis, and detailed description of all of the related stressors is beyond the scope of this analysis. What is important is the formidable body of literature unequivocally supporting the notion that stress exacerbates chronic pain. ${ }^{67-69}$ Although the impact of stress on chronic pain experience has been studied extensively, investigation of the impact of societal stress on chronic pain has been limited.

Scientists have already begun to address issues of chronic pain treatment as affected by the COVID-19 crisis. Eccleston et $\mathrm{al}^{70}$ have noted that the crisis and response of social distancing have resulted in many having to postpone evaluation and the initiation of treatment due to the misguided view that pain management is "elective." As the authors express concern that patients with pain will turn to the streets and seek potentially deadly illicit opioids, they recommend that technologies such as telemedicine and digital therapeutics emphasizing effective self-management should be used more widely. Cohen et $\mathrm{al}^{71}$ have recently developed a best practices guideline for chronic pain management during the COVID-19 pandemic and other public health crises. The authors note that "Traditionally, pain management has not been considered a high priority in austere environments or times of crisis" (p. 5). Like Eccleston et al, ${ }^{70}$ they support telehealth, and opine that utilization of mobile approaches for psychological treatment of chronic pain is perhaps even more compelling than such approaches for physical treatment. Certainly to their credit, in discussing appropriate triage, Cohen et al note the importance of assessing psychiatric considerations. Further, they cite the empirical literature indicating that psychological stress increases the risk for opioid abuse, noting that many patients consciously or unconsciously use opioids to reduce psychological symptoms that may emerge or be exacerbated by the stress of a pandemic. Unique stressors, including those associated with being quarantined, are outlined.

Overall, the body of literature on BPD and chronic pain strongly supports our concerns regarding treating previously diagnosed BPD patients. Moreover, it is important to be 
aware of the likelihood that those who are predisposed to the characterological disturbance will manifest BPD in response to the severe stress of the COVID-19 crisis. Social media has suggested that myriad patients were unable to find adequate pain treatment prior to the onset of the pandemic, reporting that they were discharged from multiple practices "without cause". It is our sense that many of these patients suffer from BPD, and as clinicians, we understand why physicians may not desire to work with these individuals. However, we also believe that pain management should be provided to all in need of such, and discrimination against these individuals presents an ethical imbroglio. All patients suffering from chronic pain deserve a chance to lead quality lives, even if they are at risk for impulsivity, suicidality, opioid misuse, and disruptive or even violent behavior. While medical systems tend to place the blame on patients for behaviors associated with their personality disorders, ${ }^{72}$ doing so is a violation of epistemic justice, ${ }^{73,74}$ and serves to further marginalize an already stigmatized, vulnerable group of patients.

We conclude by recommending that at this particularly stressful time, the key to solving the BPD and chronic pain dilemma is more routine screening for personality disorders among all patients receiving pain management services. With progressive frequency, physicians who treat patients with pain are administering screening measures for depression and anxiety, with recent recommendations made for such screening among patients in chronic pain management involving opioid therapy, ${ }^{75}$ prior to spine surgery, ${ }^{76}$ in cancer care, ${ }^{77}$ and in primary care practice, generally. ${ }^{78-80}$ Further, some suggest that more frequent urine drug testing (UDT) is actually an answer to the opioid misuse problem in the pain management setting, ${ }^{81}$ with recommendations that all patients receiving chronic opioid therapy undergo monthly UDT - not to exclude patients from treatment - but rather to determine which patients require a higher degree of monitoring in order to optimize treatment safety and efficacy. This approach is similar to one proposed in a recent study of total hip and total knee arthroplasty patients, in which the authors stress screening not as a deterrent to arthroplasty, but rather as a tool to identify patients who would potentially benefit from a higher level of support and to minimize unnecessary utilization of resources. ${ }^{82}$ Would routine of screening for BPD for chronic pain patients seeking treatment not potentially result in similar outcomes, with benefits to both the patient and physician practices?

Effective screening for depression and anxiety is not necessarily less time-consuming than screening for BPD, although more numerous brief screening measures for depression and anxiety have been validated. Undoubtedly, the choice of a BPD screening measure is an important one. Although structured and semi-structured interviews are considered the "gold standards" for the diagnosis of personality disorders, these approaches require a considerable amount of training, expertise and physician time to administer. Accordingly, they cannot be considered practical for use in the pain setting for screening patients for BPD.

While a number of screening measures for personality disorders exist, we believe that the most effective and practical for routine screening of BPD in the pain management setting is the McLean Screening Instrument for Borderline Personality Disorder (MSI-BPD). ${ }^{83}$ Numerous screening measures for all of the DSM personality disorders have been published, ${ }^{84}$ yet as they screen for multiple personality disorders, they tend to be lengthy and screen for disturbances that may not be particularly relevant to chronic pain management. The MSI-BPD is a 10 -item measure specific to BPD. Its balance of sensitivity (0.81) and specificity $(0.85)$ have been determined to be good. ${ }^{83}$ While not widely used in investigations of the impact of BPD on chronic pain outcomes, the general psychometric properties of the measure are sufficiently strong to justify it as a quick screener for BPD. Positive scores on the MSIBPD should never be used to exclude a patient with pain from treatment. As it is merely a screener, the tool should be used to identify patients who may likely benefit from psychological or psychiatric evaluation prior to continuing with treatment. Screening should be provided to all patients in a pain practice in order to 1) avoid stigmatizing those suspected of having a BPD, and 2) identify those who potentially do suffer from a BPD yet have not manifested it in their interactions with a practice, yet have the potential to manifest the symptoms in response to high levels of stress. This is particularly important during the ongoing COVID-19 crisis, as patients with chronic pain are dealing not only with their "normal" pain-related stressors but also with remote treatment or a complete lack of treatment, as well as concerns regarding medication shortages and lack of access to alternative and multimodal care. $^{70}$

Chronic pain patient advocates have expressed concern that identification of patients with BPD will result in many not being able to receive treatment. This is hardly the recommendation that we are making. Should a patient receive a diagnosis of a $\mathrm{BPD}$, he/she should be more closely monitored than non-characterologically-disturbed 
patients, just as those with greater potential for prescription opioid misuse should be monitored for such more closely than those at lower risk. ${ }^{85,86}$ Perhaps the analogy of patients at higher risk for substance abuse can be taken further in considering those with BPD. It has been recommended that patients at higher risk for substance abuse can be effectively treated in outpatient pain clinic settings, provided that they work concomitantly with a substance abuse counselor and/or an addiction medicine specialist. ${ }^{87}$ Accordingly, we recommend not that those with BPD are excluded from necessary treatment that is often necessitated for patients to lead lives of reasonable quality, but that they also receive concomitant mental health services (including Dialectical Behavioral Therapy) in order to help them minimize the behaviors that have too often resulted in their discharge from pain care and often futile efforts to find new pain management specialists to treat them. A perusal of social media over the past 3 months is suggestive of widespread psychological deterioration of many chronic pain patients, with evidence of high levels of vitriol, frank paranoia, and threats regarding selfdestructive behaviors (eg, seeking illicit opioids on the streets, suicidality) and outward violence more frequent than had been the case prior to the onset of the COVID-19 crisis. We appreciate that several months of social media posts hardly represent empirical "data", and that changes in the social media environment may occur as the pandemic progresses, stagnates, or diminishes. Irrespective, we find the trends in borderline types of posts disturbing, and are concerned that many patients will experience difficulties in finding and/or maintaining the relationships necessary to access reasonable-quality pain management. Having made recommendations for screening, referral, and enhanced monitoring, we understand that they will not be universally accepted. Further, we recognize that there will undoubtedly be a degree of variance regarding how patients with comorbid chronic pain and BPD are most effectively managed within individual pain management practices. Irrespective, it would perhaps behoove pain management physicians and their patients to ask themselves 1) are outcomes under the current paradigm of treating all patients presenting for treatment satisfactory?, and 2) can risks to both patients and their physicians be further mitigated by screening for BPD?

BPDs are not "going away", and it appears likely that the COVID-19 crisis is not going to "go away" anytime soon. The stress of poorly managed chronic pain, according to the diathesis-stress theory, is likely to result in increasing levels of stress and, accordingly, increased emotional dysregulation and related behaviors among those suffering from BPD as the COVID-19 crisis persists. Although not a panacea, the simple act of screening all chronic pain patients for BPD may represent an important initial step in identifying patients in pain practices that can benefit from further mental health evaluation and increased monitoring. Perhaps we should have looked at such a paradigm as prudent since the inception of the management of chronic pain. Irrespective, the ongoing COVID-19 crisis gives us even more reason to institute a minor paradigmatic revision in our assessment and treatment of patients with chronic pain.

\section{Disclosure}

The authors report no conflicts of interest in this work.

\section{References}

1. Giordano J, Schatman ME. An ethical analysis of crisis in chronic pain care. Part 1. Facts, issues, and problems in pain medicine. Pain Physician. 2008;11:483-490.

2. Schatman ME, Lebovits AH. On the transformation of the "profession" of pain medicine to the "business" of pain medicine: an introduction to a special series. Pain Med. 2011;12(3):403-405. doi:10.1111/j.1526-4637.2011.01059.x

3. Schatman ME, Webster LR. The health insurance industry: perpetuating the opioid crisis through policies of cost-containment and profitability. J Pain Res. 2015;8:153-158. doi:10.2147/JPR.S83368

4. Fudin J, Pratt Cleary J, Schatman ME. The MEDD myth: the impact of pseudoscience on pain research and prescribing guideline development. J Pain Res. 2016;9:153-156. doi:10.2147/JPR.S107794

5. Loeser JD, Schatman ME. Chronic pain management in medical education: a disastrous omission. Postgrad Med. 2017;129 (3):332-335. doi:10.1080/00325481.2017.1297668

6. Keppel Hesselink J, Schatman M. "But that is your opinion": the dark side of postmodern pain medicine creating a postmodern patient autonomy. J Pain Res. 2018;11:2847-2851. doi:10.2147/JPR. S188618

7. Singer JA, Sullum JZ, Schatman ME. Today's nonmedical opioid users are not yesterday's patients: implications of data indicating stable rates of nonmedical and pain reliever use disorder. $J$ Pain Res. 2019;12:617-620. doi:10.2147/JPR.S199750

8. Lo Bianco G, Thomson S, Vigneri S, Shapiro H, Schatman ME. Abdominal epilepsy, a rare cause of abdominal pain: the need to investigate thoroughly as opposed to making rapid attributions of psychogenic causality. J Pain Res. 2020;13:457-460. doi:10.2147/ JPR.S247767

9. Ilgen MA, Bohnert ASB, Ganoczy D, Bair MJ, McCarthy JF, Blow FC. Opioid dose and risk of suicide. Pain. 2016;157 (5):1079-1084. doi:10.1097/j.pain.0000000000000484

10. Oquendo MA, Volkow ND. Suicide: a silent contributor to opioid overdose deaths. $N$ Engl J Med. 2018;378(17):1567-1569. doi:10.1056/NEJMp1801417

11. Perez HR, Buonora M, Cunningham CO, Heo M, Starrels JL. Opioid taper is associated with subsequent termination of care: a retrospective cohort study. J Gen Intern Med. 2020;35(1):36-42. doi:10.1007/s11606-019-05227-9

12. Lembke A. Tapering long-term opioid therapy. Am Fam Physician. 2020;101(1):49-52. 
13. Means-Christensen AJ, Roy-Byrne PP, Sherbourne CD, Craske MG, Stein MB. Relationships among pain, anxiety, and depression in primary care. Depress Anxiety. 2008;25(7):593-600. doi:10.1002/ da. 20342

14. Tajerian M, Leu D, Zou Y, et al. Brain neuroplastic changes accompany anxiety and memory deficits in a model of complex regional pain syndrome. Anesthesiology. 2014;121(4):852-865. doi:10.1097/ ALN.0000000000000403

15. Fishbain DA, Cutler R, Rosomoff HL, Rosomoff RS. Chronic pain-associated depression: antecedent or consequence of chronic pain? A review. Clin J Pain. 1997;13(2):116-137. doi:10.1097/ 00002508-199706000-00006

16. Gureje O, Von Korff M, Kola L, et al. The relation between multiple pains and mental disorders: results from the World Mental Health Surveys. Pain. 2008;135(1-2):82-91. doi:10.1016/j.pain.2007.05.005

17. Kroenke K, Wu J, Bair MJ, Krebs EE, Damush TM, Tu W. Reciprocal relationship between pain and depression: a 12-month longitudinal analysis in primary care. J Pain. 2011;12:964-973. doi:10.1016/j.jpain.2011.03.003

18. Gureje O. Comorbidity of pain and anxiety disorders. Curr Psychiatry Rep. 2008;10(4):318-322. doi:10.1007/s11920-008-0051-0

19. Arola HM, Nicholls E, Mallen C, Thomas E. Self-reported pain interference and symptoms of anxiety and depression in community-dwelling older adults: can a temporal relationship be determined? Eur J Pain. 2010;14(9):966-971. doi:10.1016/j. ejpain.2010.02.012

20. Robb LP, Cooney JM, McCrory CR. Evaluation of spinal cord stimulation on the symptoms of anxiety and depression and pain intensity in patients with failed back surgery syndrome. Ir $\mathrm{J} \mathrm{Med}$ Sci. 2017;186(3):767-771. doi:10.1007/s11845-017-1565-4

21. Large RG. The psychiatrist and the chronic pain patient: 172 anecdotes. Pain. 1980;9(2):253-263. doi:10.1016/0304-3959(80)90012-3

22. Large RG. DSM-III diagnoses in chronic pain. Confusion or clarity? J Nerv Ment Dis. 1986;174(5):295-303. doi:10.1097/00005053198605000-00006

23. Reich J, Tupin JP, Abramowitz SI. Psychiatric diagnosis of chronic pain patients. Am J Psychiatry. 1983;140(11):1495-1498.

24. Fishbain DA, Goldberg M, Meagher BR, Steele R, Rosomoff H. Male and female chronic pain patients categorized by DSM-III psychiatric diagnostic criteria. Pain. 1986;26(2):181-197. doi:10.1016/ 0304-3959(86)90074-6

25. Gatchel RJ, Polatin PB, Kinney RK. Predicting outcome of chronic back pain using clinical predictors of psychopathology: a prospective analysis. Health Psychol. 1995;14(5):415-420. doi:10.1037/02786133.14.5.415

26. American Psychiatric Association. Diagnostic and Statistical Manual of Mental Disorders. 5th ed. Arlington, VA: American Psychiatric Publishing; 2013.

27. Elliott TR, Jackson WT, Layfield M, Kendall D. Personality disorders and response to outpatient treatment of chronic pain. J Clin Psychol Med Settings. 1996;3(3):219-234. doi:10.1007/BF01993908

28. Lenzenweger MF, Lane MC, Loranger AW, Kessler RC. DSM-IV personality disorders in the National Comorbidity Survey Replication. Biol Psychiatry. 2007;62(6):553-564. doi:10.1016/j. biopsych.2006.09.019

29. Frankenburg FR, Zanarini MC. The association between borderline personality disorder and chronic medical illnesses, poor health-related lifestyle choices, and costly forms of health care utilization. J Clin Psychiatry. 2004;65(12):1660-1665. doi:10.4088/ JCP.v65n1211

30. Alciati A, Sarzi-Puttini P, Batticciotto A, et al. Overactive lifestyle in patients with fibromyalgia as a core feature of bipolar spectrum disorder. Clin Exp Rheumatol. 2012;30(6 Suppl 74):122-128.

31. Sansone RA, Sansone LA. Borderline personality disorder in the medical setting: suggestive behaviors, syndromes, and diagnoses. Innov Clin Neurosci. 2015;12(7-8):39-44.
32. Sansone RA, Sansone LA. Borderline personality in the medical setting. Prim Care Companion CNS Disord. 2015;17(3). doi:10.4088/PCC.14r01743

33. Sansone RA, Sansone LA. Borderline personality and the pain paradox. Psychiatry (Edgmont). 2007;4(4):40-46.

34. Reynolds CJ, Carpenter RW, Tragesser SL. Accounting for the association between BPD features and chronic pain complaints in a pain patient sample: the role of emotion dysregulation factors. Personal Disord. 2018;9(3):284-289. doi:10.1037/per0000237

35. Biskin RS, Frankenburg FR, Fitzmaurice GM, Zanarini MC. Pain in patients with borderline personality disorder. Personal Ment Health. 2014;8(3):218-227. doi:10.1002/pmh.1265

36. Tragesser SL, Jones RE, Robinson RJ, Stutler A, Stewart A. Borderline personality disorder features and risk for prescription opioid use disorders. J Pers Disord. 2013;27(4):427-441. doi:10.1521/pedi_2013_27_094

37. Dulit RA, Fyer MR, Haas GL, et al. Substance use in borderline personality disorder. Am J Psychiatry. 1990;147:1002-1007.

38. Sansone RA, Watts DA, Wiederman MW. The misuse of prescription pain medication and borderline personality symptomatology. J Opioid Manag. 2013;9(4):275-279. doi:10.5055/jom.2013.0169

39. Feely MA, Havyer RD, Lapid MI, Swetz KM. Management of end-of-life care and of difficult behaviors associated with borderline personality disorder. J Pain Symptom Manage. 2013;45(5):934-938. doi:10.1016/j.jpainsymman.2012.04.004

40. Reynolds CJ, Vest N, Tragesser SL. Borderline personality disorder features and risk for prescription opioid misuse in a chronic pain sample: roles for identity disturbances and impulsivity. J Pers Disord. 2019;1-18. doi:10.1521/pedi_2019_33_440

41. Sansone RA, Sansone LA. Chronic pain syndromes and borderline personality. Innov Clin Neurosci. 2012;9(1):10-14.

42. Kalira V, Treisman GJ, Clark MR. Borderline personality disorder and chronic pain: a practical approach to evaluation and treatment. Curr Pain Headache Rep. 2013;17(8):350. doi:10.1007/s11916-013-0350-y

43. Soloff PH, Lynch KG, Kelly TM, Malone KM, Mann JJ. Characteristics of suicide attempts of patients with major depressive episode and borderline personality disorder: a comparative study. Am J Psychiatry. 2000;157(4):601-608. doi:10.1176/appi.ajp.157.4.601

44. Brown MZ, Comtois KA, Linehan MM. Reasons for suicide attempts and nonsuicidal self-injury in women with borderline personality disorder. J Abnorm Psychol. 2002;111(1):198-202. doi:10.1037/ 0021-843X.111.1.198

45. Paris J, Zweig-Frank H. A 27-year follow-up of patients with borderline personality disorder. Compr Psychiatry. 2001;42(6):482-487. doi:10.1053/comp.2001.26271

46. Paris J. Suicidality in borderline personality disorder. Medicina (Kaunas). 2019;55(6):E223.ff. doi:10.3390/medicina55060223

47. Tang NK, Crane C. Suicidality in chronic pain: a review of the prevalence, risk factors and psychological links. Psychol Med. 2006;36(5):575-586. doi:10.1017/S0033291705006859

48. Braden JB, Sullivan MD. Suicidal thoughts and behavior among adults with self-reported pain conditions in the national comorbidity survey replication. J Pain. 2008;9(12):1106-1115. doi:10.1016/j. jpain.2008.06.004

49. Campbell G, Bruno R, Darke S, Degenhardt L. Associations of borderline personality with pain, problems with medications and suicidality in a community sample of chronic non-cancer pain patients prescribed opioids for pain. Gen Hosp Psychiatry. 2015;37 (5):434-440. doi:10.1016/j.genhosppsych.2015.05.004

50. Burton K, Polatin PB, Gatchel RJ. Psychosocial factors and the rehabilitation of patients with chronic work-related upper extremity disorders. J Occup Rehabil. 1997;7(3):139-153. doi:10.1007/ BF02767360

51. Sansone RA, Hruschka J, Vasudevan A, Miller SN. Disability and borderline personality symptoms. Psychosomatics. 2003;44(5):442. doi:10.1176/appi.psy.44.5.442 
52. Knudsen AK, Skogen JC, Harvey SB, et al. Personality disorders, common mental disorders and receipt of disability benefits: evidence from the British National Survey of Psychiatric Morbidity. Psychol Med. 2012;42(12):2631-2640. doi:10.1017/S0033291712000906

53. Østby KA, Czajkowski N, Knudsen GP, et al. Personality disorders are important risk factors for disability pensioning. Soc Psychiatry Psychiatr Epidemiol. 2014;49(12):2003-2011. doi:10.1007/s00127014-0878-0

54. Reynolds CJ, Tragesser SL. Borderline personality disorder features are associated with concurrent pain-related disability in a chronic pain sample. Pain Med. 2019;20(2):233-245. doi:10.1093/pm/ pny052

55. Crowell SE, Beauchaine TP, Linehan MM. A biosocial developmental model of borderline personality: elaborating and extending Linehan's theory. Psychol Bull. 2009;135(3):495-510. doi:10.1037/ a0015616

56. Perez-Rodriguez MM, Bulbena-Cabré A, Bassir Nia A, Zipursky G, Goodman M, New AS. The neurobiology of borderline personality disorder. Psychiatr Clin North Am. 2018;41(4):633-650. doi:10.1016/ j.psc.2018.07.012

57. Linehan MM. Cognitive-Behavioral Treatment of Borderline Personality Disorder. New York: Guilford Press; 1993.

58. Ryan RM. The developmental line of autonomy in the etiology, dynamics, and treatment of borderline personality disorders. Dev Psychopathol. 2005;17(4):987-1006. doi:10.1017/S0954579405050467

59. Skodol AE. The borderline diagnosis: concepts, criteria, and controversies. In: Gunderson JG, Hoffman PD, editors. Understanding and Treating Borderline Personality Disorder a Guide for Professionals and Families. Washington, DC: American Psychiatric Publishing, Inc.; 2005:3-19.

60. Gunderson JG, Lyons-Ruth K. The developmental line of autonomy in the etiology, dynamics, and treatment of borderline personality disorders. Dev Psychopathol. 2008;17(4):987-1006.

61. Flor H, Turk DC. Etiological theories and treatments for chronic back pain. I. Somatic models and interventions. Pain. 1984;19(2):105-121.

62. Turk DC, Flor H. Etiological theories and treatments for chronic back pain. II. Psychological models and interventions. Pain. 1984;19 (3):209-233

63. Weisberg JN, Keefe FJ. Personality, individual differences, and psychopathology in chronic pain. In: Gatchel RJ, Turk DC, editors. Psychosocial Factors in Pain: Critical Perspectives. New York: The Guilford Press; 1999:56-73.

64. Weisberg JN, Keefe FJ. Personality disorders in the chronic pain population: basic concepts, empirical findings, and clinical implications. Pain Forum. 1997;6:1-9. doi:10.1016/S1082-3174(97) 70001-1

65. Weisberg JN. Personality and personality disorders in chronic pain. Curr Rev Pain. 2000;4(1):60-70. doi:10.1007/s11916-000-0011-9

66. Weisberg JN, Vittengl JR, Clark LA, Gatchel RJ, Gorin AA. Personality and pain: summary and future perspectives. In: Gatchel RJ, Weisberg JN, editors. Personality Characteristics of Patients with Pain. Washington, DC: American Psychological Association; 2000:259-282.

67. Lumley MA, Cohen JL, Borszcz GS, et al. Pain and emotion: a biopsychosocial review of recent research. J Clin Psychol. 2011;67(9):942-968. doi:10.1002/jclp.20816

68. Ahmad AH, Zakaria R. Pain in times of stress. Malays J Med Sci. 2015;22(SpecIssue):52-61.

69. Vachon-Presseau E. Effects of stress on the corticolimbic system: implications for chronic pain. Prog Neuropsychopharmacol Biol Psychiatry. 2018;87(Pt B):216-223. doi:10.1016/j.pnpbp.2017.10.014

70. Eccleston C, Blyth FM, Dear BF, et al. Managing patients with chronic pain during the COVID-19 outbreak: considerations for the rapid introduction of remotely supported (eHealth) pain management services. Pain. 2020;161(5):889-893. doi:10.1097/j.pain.00000000 00001885
71. Cohen SP, Baber ZB, Buvanendran A, et al. Pain management best practices from multispecialty organizations during the COVID-19 pandemic and public health crises. Pain Med. 2020;pii:pnaa127. doi:10.1093/pm/pnaa127

72. Brunero S, The LS. 'difficult' nurse-patient relationship: development and evaluation of an e-learning package. Contemp Nurse. 2010;35(2):136-146. doi:10.5172/conu.2010.35.2.136

73. Kyratsous M, Sanati A. Epistemic injustice and responsibility in borderline personality disorder. J Eval Clin Pract. 2017;23 (5):974-980. doi:10.1111/jep.12609

74. Knaak S, Mantler E, Szeto A. Mental illness-related stigma in healthcare: barriers to access and care and evidence-based solutions. Healthc Manage Forum. 2017;30(2):111-116. doi:10.1177/ 0840470416679413

75. van Rijswijk SM, van Beek MHCT, Schoof GM, Schene AH, Steegers M, Schellekens AF. Iatrogenic opioid use disorder, chronic pain and psychiatric comorbidity: a systematic review. Gen Hosp Psychiatry. 2019;59:37-50. doi:10.1016/j.genhosppsych.2019.04.008

76. Harris AB, Marrache M, Puvanesarajah V, et al. Are preoperative depression and anxiety associated with patient-reported outcomes, health care payments, and opioid use after anterior discectomy and fusion? Spine J. 2020: S1529-9430(20)30096. doi:10.1016/j. spinee.2020.03.004.

77. Shepherd HL, Geerligs L, Butow P, et al. The elusive search for success: defining and measuring implementation outcomes in a real-world hospital trial. Front Public Health. 2019;7:293. doi:10.3389/fpubh.2019.00293

78. Larvin H, Peckham E, Prady SL. Case-finding for common mental disorders in primary care using routinely collected data: a systematic review. Soc Psychiatry Psychiatr Epidemiol. 2019;54(10):1161-1175. doi:10.1007/s00127-019-01744-4

79. Rajesh R, Tampi R, Balachandran S. The case for behavioral health integration into primary care. J Fam Pract. 2019;68(5):278-284.

80. Jha MK, Grannemann BD, Trombello JM, et al. A structured approach to detecting and treating depression in primary care: vitalSign6 Project. Ann Fam Med. 2019;17(4):326-335. doi:10.1370/afm. 2418

81. DiBenedetto DJ, Wawrzyniak KM, Schatman ME, Shapiro H, Kulich RJ. Increased frequency of urine drug testing in chronic opioid therapy: rationale for strategies for enhancing patient adherence and safety. J Pain Res. 2019;12:2239-2246. doi:10.2147/JPR. S213536

82. Stone AH, MacDonald JH, King PJ. The effect of psychiatric diagnosis and psychotropic medication on outcomes following total hip and total knee arthroplasty. J Arthroplasty. 2019;34(9):1918-1921. doi:10.1016/j.arth.2019.04.064

83. Zanarini MC, Vujanovic AA, Parachini EA, Boulanger JL, Frankenburg FR, Hennen J. A screening measure for BPD: the McLean Screening Instrument for Borderline Personality Disorder (MSI-BPD). J Pers Disord. 2003;17(6):568-573. doi:10.1521/ pedi.17.6.568.25355

84. Zimmerman M, Balling C. Screening for borderline personality disorder with the McLean Screening Instrument: a review and critique of the literature. $J$ Pers Disord. 2019;1-11. doi:10.1521/ pedi_2019_33_451

85. Kaye AD, Jones MR, Kaye AM, et al. Prescription opioid abuse in chronic pain: an updated review of opioid abuse predictors and strategies to curb opioid abuse: part 1. Pain Physician. 2017;20 (2S):S93-S109. doi:10.36076/ppj.2017.s111

86. Kaye AD, Jones MR, Kaye AM, et al. Prescription opioid abuse in chronic pain: an updated review of opioid abuse predictors and strategies to curb opioid abuse: part 2. Pain Physician. 2017;20 (2S):S111-S133.

87. Vaughn IA, Beyth R, Ayers ML, et al. Multispecialty opioid risk reduction program targeting chronic pain and addiction management in veterans. Fed Pract. 2019;36(9):406-411. 


\section{Publish your work in this journal}

The Journal of Pain Research is an international, peer reviewed, open access, online journal that welcomes laboratory and clinical findings in the fields of pain research and the prevention and management of pain. Original research, reviews, symposium reports, hypothesis formation and commentaries are all considered for publication. The manuscript management system is completely online and includes a very quick and fair peer-review system, which is all easy to use. Visit http:// www.dovepress.com/testimonials.php to read real quotes from published authors.

Submit your manuscript here: https://www.dovepress.com/journal-of-pain-research-journal 